\title{
Racial/Ethnic Patterns of Care for Pancreatic Cancer
}

\author{
Vickie L. Shavers, Ph.D.,' Linda C. Harlan, Ph.D., \\ Monica Jackson, Ph.D., ${ }^{2}$ and JaMuir Robinson, Ph.D., M.P.H. ${ }^{3}$
}

\begin{abstract}
Introduction: The small proportion of cancers diagnosed at the local disease stage, resectable at the time diagnosis, and responsive to chemotherapy contribute to poor survival making pancreatic cancer the fourth leading cause of cancer death among Americans. This emphasizes the importance of receiving appropriate palliative care. Racial/ethnic cancer treatment disparities have been observed for many cancer sites. We examine patterns of care in a population-based sample of African American, Hispanic and non-Hispanic white patients diagnosed with pancreatic cancer.

Methods: Eligible cases were age 20 or older and newly diagnosed in 1998 with primary adenocarcinoma of the pancreas reported to the National Cancer Institute's Surveillance Epidemiology and End Results (SEER) program and selected for the NCI Patterns of Care/Quality of Care (POC/QOC) project $(n=697)$.

Results: Chemotherapy, the most frequently received treatment was less frequently received by African American patients (odds ratio [OR] 0.61, 95\% confidence interval [CI] 0.37-0.95) and radiation less frequently received by Hispanic compared to non-Hispanic white white patients (OR 0.50, 95\% CI, 0.27-0.95) after adjustment for age, stage, size of tumor, and insurance status in a multivariate regression model. Cancer-directed surgery of the primary site was received by $14.1 \%$ of patients, which did not significantly differ by race/ ethnicity. Uninsured patients less often were recommended for or received surgery (OR 0.09, 95\% CI 0.01-0.62) and (OR 0.07, 95\% CI, 0.01-0.49), respectively.

Conclusion: Differences in primary tumor size, stage and insurance status contributed to racial/ethnic differences in the receipt of cancer-directed surgery but did not explain differences in the receipt of chemotherapy for African American or radiation for Hispanic patients. More population-based research is needed to examine race/ethnicity, insurance status and receipt of treatment and palliative care for pancreatic cancer.
\end{abstract}

\section{Introduction}

C ANCER OF THE PANCREAS is the fourth leading cause of cancer death among Americans accounting for approximately $3 \%$ of overall cancer incidence and $6 \%$ of all cancer deaths. ${ }^{1}$ It is estimated that more than 37,000 new cases of cancer of the pancreas will be diagnosed among Americans and more than 34,000 deaths from cancer at this site will occur in 2008. The small proportion of cases that are potentially curable $^{2-6}$ makes palliation of symptoms a critical component of patient management ${ }^{7,8}$ because less than $24 \%$ of patients are still alive 1 year after diagnosis. ${ }^{2}$ The goals of palliative care for patients with pancreatic cancer include symptom reduction, reduction of in-hospital stays, and adequate pain management. ${ }^{9}$ Practice guidelines for the treatment of locally advanced pancreatic cancer recommend, "palliation for symptomatic patients and life prolongation in medically suitable cases." 10 Approximately $65 \%-75 \%$ of patients de- velop symptomatic biliary obstruction and 10\%-25\% symptomatic gastric outlet obstruction. ${ }^{11}$ Palliative interventions may also be required for pancreatic insufficiency, treatment of thromboembolic disease, depression, pain, and malnutrition. Treatment with surgery, radiation, or chemotherapy generally provides palliation and pain relief. Nutritional support, biliary stenting, and bowel decompression may also be provided for supportive care as appropriate.

Pancreatic cancer incidence rates for 2000-2004 were 27\% and $40 \%$ higher for African American men and women compared to non-Hispanic white men and women while the respective mortality rates were $29 \%$ and 38\% higher. ${ }^{2}$ Data from observational research studies have shown racial/ethnic disparities in receipt of cancer treatment ${ }^{12-14}$ and palliative care including receipt of effective pain medication ${ }^{15}$ and use of hospice among patients with cancer in general. ${ }^{16,17} \mathrm{How}$ ever, little is known about patterns of care for patients diagnosed with pancreatic cancer or how this might vary by

\footnotetext{
${ }^{1}$ Applied Research Program, National Cancer Institute, Bethesda, Maryland.

${ }^{2}$ Department of Mathematics and Statistics, American University, Washington, D.C.

${ }^{3}$ Walden University, Washington, D.C.
} 
racial/ethnicity. This study examined treatment for pancreatic cancer using the NCI Patterns of Care/Quality of Care (POC/QOC) population-based sample of African Americans, Hispanic, and non-Hispanic white patients.

\section{Materials and Methods}

\section{Data source}

Patients included in this analysis were registered at one of the National Cancer Institute's (NCI) Surveillance Epidemiology and End Results (SEER) programs in the study (i.e., the states of Connecticut, Iowa, New Mexico, and Utah and the metropolitan areas of Detroit, Michigan; Atlanta, Georgia; San Francisco-Oakland and San Jose-Monterey, California; Los Angeles, California; and Seattle, Washington).

The NCI (POC/QOC) studies are designed as exploratory investigations of therapy received for specific cancer sites using cases identified in the SEER registries. In general, these studies provide population-based data on therapy received during the first course of treatment by patients. However, for this study of pancreatic cancer medical record abstractors were asked to record all therapy provided regardless of the time frame and physician. These studies also provide more complete information on the receipt of outpatient treatments such as chemotherapy and radiation than the routine data collection using hospital medical records. For POC/QOC studies, hospital medical records are re-abstracted and the patient's treating physician is contacted to verify all treatments received and/or recommended and refused. The physician is also asked whether another physician provided therapy, if so that physician is also contacted.

\section{Eligibility criteria}

Individuals eligible for inclusion in this analysis were age 20 or older at diagnosis, newly diagnosed in 1998 with primary adenocarcinoma of the pancreas (ICDO-2 C25.0-C25.9) reported to one the selected SEER programs. Individuals were ineligible if they were diagnosed at autopsy or by death certificate, did not have microscopically or radiologically confirmed primary pancreatic cancer, or if they had been previously diagnosed with another primary cancer other than nonmelanoma skin cancer.

\section{Demographic characteristics}

Demographic characteristics included race/ethnicity (African American, Hispanic, non-Hispanic white), age (years), gender, and marital status (single, married, divorced, separated, widowed, or unknown). Race and Hispanic ethnicity were obtained from the hospital medical records. If ethnicity was not available, the patient's surname or maiden name was used to assess Hispanic ethnicity. Insurance status was assessed at the time of the receipt of the most definitive therapy received by the patient and was categorized as no insurance, private insurance only, $\mathrm{HMO}$ or other managed care plan, Medicaid/Medicare only and other insurance.

\section{Cancer-directed surgery}

Patients were considered to have received cancer-directed surgery if they received surgery that included resection of the primary tumor. Patients were considered to have received a recommendation for cancer-directed surgery if surgery was performed, if surgery was recommended but not performed, if surgery was recommended but unknown whether performed, or if surgery was refused. Patients were considered not to have received a recommendation for cancer-directed surgery if surgery was not recommended for the initial course of treatment (first 4 months after diagnosis) or was contraindicated due to other conditions.

\section{Chemotherapy and radiation}

Patients were categorized as having received chemotherapy or radiation if the medical record or the physician indicated that the patient received these treatments.

\section{Statistical methods}

Sampling. For this study, within each SEER registry, patients diagnosed with invasive pancreatic adenocarcinoma meeting the eligibility criteria were first stratified by race/ethnic group, gender and diagnostic confirmation (i.e., microscopic or radiographic) and then randomly sampled within strata. African Americans and Hispanics were oversampled to obtain more stable estimates.

Analytical methods. All data analyses were performed with SUDAAN (Research Triangle Institute, Research Triangle Park, NC), a statistical software program for the analysis of complex survey and correlated data. $\chi^{2}$ tests for homogeneity of proportions and $p$ values are used to evaluate racial/ethnic variation in the distribution of demographic and clinical categorical variables. $\chi^{2}$ tests are also used to separately examine the significance of differences between non-Hispanic whites and African Americans with regard to the receipt of a recommendation for cancer-directed surgery, receipt of cancer-directed surgery, receipt of chemotherapy or radiation. Multivariate logistic regression analyses were performed to examine the receipt of a recommendation for and receipt of cancer-directed surgery and receipt of chemotherapy, or radiation as treatment for pancreatic cancer. Explanatory variables examined in the multivariable analyses included age (years), gender, insurance status (insured/uninsured), the size of primary tumor $(<3 \mathrm{~cm},>3 \mathrm{~cm}$, unknown size), and comorbidity measured by the Charlson comorbidity score (i.e. 0 , 1 , and $2+$ ). All variables were entered in a multivariable model for each of the respective response variables. The comorbidity variable was removed from the models related to chemotherapy and radiation because it was not significantly associated with these outcomes. An $\alpha$ of 0.05 was used as the cut point for assessing statistical significance.

Kaplan-Meier survival analyses were used to examine 5-year overall survival (the percentage of participants that did not die from any cause and disease-specific survival) (the percentage of participants who did not die from pancreatic cancer). Stratified survival analyses and the log rank test were used to assess the statistical significance of differences in survival times between the racial/ethnic groups.

\section{Results}

\section{Demographic characteristics}

There were 2404 patients diagnosed with pancreatic cancer and reported to the SEER registries in 1998, of whom, 697 
were sampled. African Americans comprised 25.1\%; Hispanics, $18.7 \%$; and non-Hispanic whites, $56.2 \%$ of the total sample. The mean age at diagnosis overall was somewhat lower for African Americans (65.0) and Hispanics (64.2) than non-Hispanic whites $(69.7 ; p<0.001)$. Nearly $8 \%$ of Hispanics and more than $5 \%$ of African Americans had no health insurance compared to $1 \%$ of non-Hispanic whites (Table 1).

\section{Clinical characteristics}

Overall, $62.3 \%$ of patients with pancreatic cancer in this study were diagnosed with distant-stage disease. Sixty-six percent of African Americans, 62.7\% of non-Hispanic whites, and $52.5 \%$ of Hispanic patients were diagnosed with distantstage disease (Table 2). The most common location of the primary tumor was the head of the pancreas. A higher percentage of the tumors among African Americans (16.4\%) were diagnosed in the tail of the pancreas compared to Hispanics $(7.7 \%)$ and non-Hispanic whites (10.2\%). Only 5.2\% of tumors among African American were less that $3 \mathrm{~cm}$ compared to $11.3 \%$ of the tumors among Hispanics and $12.7 \%$ of the tumors among non-Hispanic whites.

\section{Receipt of cancer-directed surgery}

Cancer-directed surgery was received by only $14.1 \%$ of patients overall, including $14.8 \%$ of Hispanic, $14.5 \%$ of NHW and $10.7 \%$ of African American patients ( $p=0.365$; Table 3 ). Surgery was not recommended for $42.9 \%$ of patients, contraindicated for $8.1 \%$ and was known not to have been recommended for $44.6 \%$ of non-Hispanic whites, $36.5 \%$ of African Americans and 35.4\% of Hispanic patients. For more than $53 \%$ of African American, $52 \%$ of Hispanic and $35 \%$ of non-Hispanic white patients the reason for no cancer-directed surgery was unknown. Surgery was refused by less than $2 \%$ of African American and non-Hispanic white patients while no Hispanic patients refused surgery. While surgery was infrequent, the Whipple was the most frequently performed surgical procedure overall $(62.3 \%)$ and within each racial/ethnic group (65\% non-Hispanic whites, 47\% African Americans, 50\% Hispanics; Table 3).

In a multivariable logistic regression analysis of the receipt of cancer-directed surgery, older age (OR 0.96, 95\%CI $0.93-$ 0.98 ), distant (OR $0.08,95 \%$ CI $0.03-0.22$ ) or unstaged disease (OR 0.03, 95\% CI 0.01-0.17), tumor size greater than $3 \mathrm{~cm}(\mathrm{OR}$ $0.32,95 \%$ CI 0.14-0.72) or unknown tumor size (OR 0.07, 0.020.19 ) and a Charlson comorbidity score of 2 or more (OR 0.28 , 95\% CI 0.09-0.84) were significantly associated with lower receipt of cancer-directed surgery. Uninsured patients also had significantly lower adjusted odds of receiving cancer-directed surgery (OR 0.07, 95\% CI 0.01-0.49). Race/ethnicity was not significantly associated with the receipt of cancerdirected surgery in models adjusted for other covariates (Table 4).

In multivariate regression model of the receipt of a recommendation for cancer-directed surgery was significantly associated with primary tumor size greater than $3 \mathrm{~cm}(\mathrm{OR}$ $0.03,95 \%$ CI 0.14-0.74), unknown tumor size (OR 0.08, 95\% CI $0.03-0.23$ ), comorbidity score of 2 or more (OR $0.26,0.08$ 0.83 ), and being uninsured (OR 0.09, 0.01-0.62) after controlling for other covariates (Table 4). Race/ethnicity was not statistically associated with a recommendation for cancerdirected surgery in the adjusted model.

\section{Receipt of chemotherapy}

Chemotherapy, the most frequently received treatment, was received by $42 \%$ of patients with pancreatic cancer in this

Table 1. Demographic Characteristics of Patients Diagnosed with Pancreatic Cancer, SEER-POC, 1998 (UNWEIGHTED)

\begin{tabular}{|c|c|c|c|c|c|}
\hline & $\begin{array}{l}\text { African American } \\
\mathrm{n}^{\mathrm{a}}=175\end{array}$ & $\begin{array}{l}\text { Hispanic } \\
\mathrm{n}^{\mathrm{a}}=130\end{array}$ & $\begin{array}{l}\text { White Non-Hispanic } \\
\qquad \mathrm{n}^{\mathrm{a}}=392\end{array}$ & $\begin{array}{c}\text { Total } \\
\mathrm{n}^{\mathrm{a}}=697\end{array}$ & $\mathrm{p}$ value \\
\hline \multicolumn{6}{|l|}{ Age $^{\mathrm{b}}$} \\
\hline Mean & 65.0 & 64.2 & 69.7 & 67.5 & $<0.001$ \\
\hline Median & 65 & 67 & 70 & - & - \\
\hline \multicolumn{6}{|l|}{ Gender } \\
\hline Male & 46.9 & 42.3 & 49.0 & 47.2 & \\
\hline Female & 53.1 & 57.7 & 51.0 & 52.8 & 0.413 \\
\hline \multicolumn{6}{|l|}{ Marital status ${ }^{\mathrm{b}}$} \\
\hline Single & 20.0 & 13.8 & 11.0 & 13.8 & \\
\hline Married & 44.6 & 53.1 & 57.7 & 53.5 & \\
\hline Divorced & 1.1 & 1.5 & 0.3 & 0.7 & \\
\hline Separated & 13.7 & 9.2 & 5.4 & 8.2 & $<0.001$ \\
\hline Widowed & 18.3 & 16.2 & 24.2 & 21.2 & \\
\hline Unknown & 2.3 & 6.2 & 1.5 & 2.6 & \\
\hline \multicolumn{6}{|l|}{ Insurance status ${ }^{c}$} \\
\hline No insurance & 5.1 & 7.7 & 1.0 & 3.3 & \\
\hline Private only (non-HMO) & 13.7 & 12.3 & 18.9 & 16.4 & \\
\hline HMO or other managed care plan & 22.9 & 28.5 & 19.9 & 22.2 & $<0.001$ \\
\hline Medicaid/Medicare only & 33.7 & 37.7 & 23.0 & 28.4 & \\
\hline Other insurance & 24.6 & 13.9 & 37.2 & 29.7 & \\
\hline
\end{tabular}

${ }^{a} n=$ Unweighted sample size for the indicated analysis. Numbers may differ from the total sample size indicated because of missing data. Proportions are weighted.

bSEER 1998.

'Patterns of Care, 1998. 
Table 2. Initial Clinical Characteristics of Patients Diagnosed with Pancreatic Cancer, SEER-POC, 1998 (WEIGHTED PERCENT)

\begin{tabular}{|c|c|c|c|c|c|}
\hline Clinical variable & $\begin{array}{c}\text { African } \\
\text { American } \\
{ }^{\mathrm{a}} \mathrm{n}=175\end{array}$ & $\begin{array}{l}\text { Hispanic } \\
{ }^{\mathrm{a}} \mathrm{n}=130\end{array}$ & $\begin{array}{c}\text { White } \\
\text { Non-Hispanic } \\
\mathrm{a} n=392\end{array}$ & $\begin{array}{c}\text { Total } \\
{ }^{\mathrm{a}} \mathrm{n}=697\end{array}$ & $\mathrm{p}$ value \\
\hline \multicolumn{6}{|l|}{ Stage $\mathrm{b}^{\mathrm{b}}$} \\
\hline Local & 6.0 & 5.9 & 5.7 & 5.8 & \multirow{4}{*}{0.117} \\
\hline Regional & 18.6 & 29.1 & 25.1 & 24.6 & \\
\hline Distant & 66.0 & 52.5 & 62.7 & 62.3 & \\
\hline Unstaged & 9.4 & 12.5 & 6.6 & 7.3 & \\
\hline \multicolumn{6}{|l|}{ Size of primary tumor ${ }^{\mathrm{b}}(\mathrm{cm})$} \\
\hline$<3 \mathrm{~cm}$ & 5.2 & 11.3 & 12.7 & 11.7 & \multirow{4}{*}{0.006} \\
\hline $3-4.9 \mathrm{~cm}$ & 23.7 & 16.9 & 27.3 & 26.0 & \\
\hline 5 or more $\mathrm{cm}$ & 23.9 & 20.0 & 18.4 & 19.2 & \\
\hline Unknown & 47.3 & 51.9 & 41.6 & 43.1 & \\
\hline Mean and median size of tumors with known size & ${ }^{a} n=94$ & ${ }^{a} n=59$ & ${ }^{\mathrm{a}} n=208$ & ${ }^{a} n=361$ & \multirow{3}{*}{0.693} \\
\hline Mean tumor size & 4.8 & 4.7 & 4.5 & 4.7 & \\
\hline Median tumor size & 4.0 & 4.0 & 4.0 & - & \\
\hline \multicolumn{6}{|l|}{ Location of primary tumor ${ }^{b}$} \\
\hline Head of pancreas (C25.0) & 49.1 & 55.1 & 54.1 & 53.6 & \multirow{7}{*}{$<0.001$} \\
\hline Body of pancreas (C25.1) & 6.4 & 2.2 & 11.1 & 9.9 & \\
\hline Tail of pancreas (C25.2) & 16.4 & 7.7 & 10.2 & 10.8 & \\
\hline Pancreatic duct (C25.3) & 0 & 0.7 & 1.5 & 1.3 & \\
\hline Islets of Langerhans (C25.4) & 0 & 0 & 0.2 & 0.2 & \\
\hline Pancreas and other, NOS (C25.9) & 17.5 & 17.9 & 16.5 & 16.7 & \\
\hline Other/overlapping lesions of pancreas (C25.7-C25.8) & 10.6 & 16.4 & 6.4 & 7.7 & \\
\hline \multicolumn{6}{|l|}{ Comorbidity ${ }^{\mathrm{c}}$} \\
\hline \multicolumn{6}{|l|}{ Charlson co-morbidity score } \\
\hline 0 & 66.0 & 58.6 & 63.2 & 63.1 & \multirow{3}{*}{0.614} \\
\hline 1 & 24.6 & 33.5 & 27.4 & 27.6 & \\
\hline 2 or more & 9.4 & 7.9 & 9.4 & 9.3 & \\
\hline
\end{tabular}

${ }^{a} n=$ unweighted sample size for the indicated analysis. Numbers may differ from the total sample size indicated because of missing data. Proportions are weighted.

${ }^{\mathrm{b}}$ SEER 1998.

'Patterns of Care, 1998.

study. Receipt of chemotherapy varied by race/ethnicity with $34.2 \%$ of African Americans receiving chemotherapy compared to $42.4 \%$ of Hispanics and $43.2 \%$ of non-Hispanic white patients (Table 3) but this was not a statistically significant difference in unadjusted analyses. Chemotherapy was refused by $7.4 \%$ of African Americans, $7.2 \%$ of non-Hispanic whites, and $8.2 \%$ of Hispanics $(p=0.960)$.

African Americans were significantly less likely to receive chemotherapy for their pancreatic cancer (OR 0.61, 95\% CI 0.37-0.95) compared to non-Hispanic whites in the adjusted logistic regression model. The odds of receiving chemotherapy decreased with increasing years of age (OR 0.94, 95\% CI 0.92-0.96). Patients with regional stage disease were significantly more likely to receive chemotherapy compared to those with local stage disease (OR 2.53, 95\% CI 1.01-6.30). The most frequently received chemotherapeutic agents were 5 -flurouracil (21.7\%) and gemcitabine (20.4\%). There were no significant differences between the race/ethnic groups with respect to specific agents (data not presented).

\section{Receipt of radiation}

Radiation was received by $20.4 \%$ of patients with pancreatic cancer. Radiation was most frequently received in conjunction with chemotherapy (either before, after, or concurrently; Table 3). In the unadjusted analyses radiation did not significantly vary by race/ethnicity, which was received by $15.5 \%$ of Hispanics, $16.4 \%$ of African American, and $21.5 \%$ of non-Hispanic white patients ( $p=0.223$; Table 3$)$.

In a multivariable logistic regression model that examined receipt of radiation, Hispanic patients were significantly less likely than non-Hispanic whites to receive radiation (OR 0.50, 95\% CI 0.27-0.95; Table 4) after adjustment for other covariates. Although there was less frequent receipt of radiation among African Americans compared to non-Hispanic whites this was not a statistically significant finding. Patients with distant and unstaged disease also less frequently received radiation which also decreased with increased age.

\section{Survival}

Both the median overall and disease-specific survival times was 4 months while the mean was 9.6 months and 8.1 months, respectively (data not presented in tables). The three race/ethnic groups did not significantly differ in terms of either the mean or median overall survival. The mean and median overall survival times were 8.1 and 4 months for African Americans, 10 and 6 months for Hispanics, and 9.5 and 4 months for non-Hispanic whites, respectively. The mean and median disease specific survival times were 6.5 and 3 months for African Americans, 8.9 and 4.5 months for Hispanics, and 8.2 and 4 months for non-Hispanic whites, respectively. 
Table 3. Patterns of Care for Patients Diagnosed with Pancreatic Cancer, SeER-POC, 1998 (weighted percent)

\begin{tabular}{|c|c|c|c|c|c|}
\hline & $\begin{array}{c}\text { African } \\
\text { American } \\
{ }^{\mathrm{a}} \mathrm{n}=175\end{array}$ & $\begin{array}{l}\text { Hispanic } \\
{ }^{a} \mathrm{n}=130\end{array}$ & $\begin{array}{c}\text { Non-Hispanic } \\
\text { white } \\
{ }^{a} n=392\end{array}$ & $\begin{array}{c}\text { Total } \\
{ }_{\mathrm{a}} \mathrm{n}=697\end{array}$ & $\mathrm{p}$ value \\
\hline \multicolumn{6}{|l|}{ Site-specific surgery } \\
\hline No cancer directed surgery of primary site & 89.3 & 85.2 & 85.5 & 85.9 & 0.365 \\
\hline Received cancer directed surgery of primary site & 10.7 & 14.8 & 14.5 & 14.1 & \\
\hline \multicolumn{6}{|l|}{ Type of surgery (among those receiving surgery) } \\
\hline Partial pancreatectomy, NOS & 18.1 & 10.6 & 14.2 & 14.3 & \\
\hline Total pancreatectomy & 7.6 & 0 & 0 & 0.7 & 0.084 \\
\hline $\begin{array}{l}\text { Total pancreatectomy with subtotal gastrectomy or } \\
\text { duodectomy. }\end{array}$ & 0 & 4.4 & 10.6 & 9.2 & \\
\hline Local or partial pancreatectomy and duodenectomy & 0 & 13.0 & 2.6 & 3.2 & \\
\hline Without subtotal gastrectomy & 15.2 & 4.4 & 2.8 & 4.0 & \\
\hline With subtotal gastrectomy (Whipple) & 46.7 & 49.6 & 65.2 & 62.3 & \\
\hline Extended pancreatoduodedenectomy & 0 & 9.7 & 2.2 & 2.6 & \\
\hline Pancreatectomy, NOS & 0 & 0 & 1.5 & 1.3 & \\
\hline Surgery, NOS & 0 & 4.1 & 0.8 & 1.0 & \\
\hline Unknown if cancer directed surgery performed & 12.3 & 4.2 & 0 & 1.4 & \\
\hline \multicolumn{6}{|c|}{ Reason no cancer-directed surgery (among those not receiving surgery) } \\
\hline Cancer directed surgery not recommended & 36.5 & 35.4 & 44.6 & 42.9 & \\
\hline Contraindicated due to other conditions & 4.1 & 6.1 & 8.9 & 8.1 & \\
\hline Unknown reason for no cancer-directed surgery & 53.2 & 52.3 & 35.4 & 38.8 & $<0.0001$ \\
\hline Cancer directed surgery was refused & 1.6 & 0 & 1.6 & 1.4 & \\
\hline Recommended unknown if done & 0 & 0 & 0.3 & 0.2 & \\
\hline Unknown if cancer directed surgery performed & 4.7 & 6.2 & 9.3 & 8.5 & \\
\hline \multicolumn{6}{|l|}{ Chemotherapy } \\
\hline Chemotherapy not given & 65.8 & 57.6 & 56.8 & 57.9 & \\
\hline Received chemotherapy & 34.2 & 42.4 & 43.2 & 42.1 & 0.130 \\
\hline \multicolumn{6}{|l|}{ Reason no chemotherapy } \\
\hline Refused chemotherapy & 7.4 & 7.2 & 8.2 & 8.0 & \\
\hline Did not refuse chemotherapy & 92.6 & 92.8 & 91.8 & 92.0 & 0.960 \\
\hline \multicolumn{6}{|l|}{ Radiation } \\
\hline Radiation not given & 83.6 & 84.5 & 78.5 & 79.6 & \\
\hline Received radiation & 16.4 & 15.5 & 21.5 & 20.4 & 0.223 \\
\hline \multicolumn{6}{|l|}{ Radiation sequence with surgery } \\
\hline No radiation and/or no cancer directed surgery & 95.5 & 93.3 & 94.0 & 94.1 & \\
\hline Radiation before surgery & 0.4 & 0 & 0.2 & 0.2 & \\
\hline Radiation after surgery & 4.1 & 5.6 & 5.2 & 5.1 & 0.436 \\
\hline Intraoperative radiation & 0 & 0.6 & 0.5 & 0.4 & \\
\hline $\begin{array}{l}\text { Intraoperative radiation with other radiation given } \\
\text { before or after surgery }\end{array}$ & 0 & 0.6 & 0.2 & 0.2 & \\
\hline \multicolumn{6}{|l|}{ Radiation therapy sequence with chemotherapy } \\
\hline No radiation and/or chemotherapy & 84.9 & 85.1 & 81.9 & 82.5 & \\
\hline Radiation before chemotherapy & 2.7 & 0 & 0.6 & 0.8 & \\
\hline Radiation after chemotherapy & 2.4 & 4.4 & 3.5 & 3.4 & 0.085 \\
\hline Concurrent radiation and chemotherapy. & 8.0 & 8.7 & 11.2 & 10.7 & \\
\hline $\begin{array}{l}\text { Concurrent radiation and chemotherapy with other } \\
\text { radiation given before or after chemotherapy }\end{array}$ & 1.3 & 0.6 & 2.2 & 1.9 & \\
\hline Chemotherapy before and after radiation & 0.8 & 0 & 0 & 0.1 & \\
\hline Both given, sequence unknown & 0 & 1.2 & 0.6 & 0.6 & \\
\hline \multicolumn{6}{|l|}{ Treated on a clinical trial protocol } \\
\hline Yes & 3.3 & 0.7 & 5.5 & 4.9 & \\
\hline No & 90.5 & 95.6 & 90.3 & 90.7 & \\
\hline Refused & 1.2 & 0 & 0.3 & 0.4 & 0.027 \\
\hline Recommended, unknown if treated on protocol & 0 & 0 & 0.9 & 0.7 & \\
\hline Unknown & 5.0 & 3.8 & 3.1 & 3.4 & \\
\hline
\end{tabular}

${ }^{\mathrm{a}} n$, Unweighted sample size for the indicated analysis. Numbers may differ from the total sample size indicated because of missing data. Proportions are weighted.

$n^{*}$ Unweighted sample size for the indicated analysis. Numbers may differ from the total sample size indicated because of missing data. Proportions are weighted. 
Table 4. Multiple Logistic Regression Analyses of Receipt of a Recommendation and Receipt of Cancer-Directed Surgery, Chemotherapy, or Radiation as Treatment for Pancreatic Cancer, SEER-POC 1998

\begin{tabular}{|c|c|c|c|c|}
\hline & $\begin{array}{c}\text { Receipt of recommendation } \\
\text { for cancer-directed surgery } \\
\text { OR }(95 \% \mathrm{CI})\end{array}$ & $\begin{array}{c}\text { Receipt of cancer-directed } \\
\text { surgery OR }(95 \% \text { CI) }\end{array}$ & $\begin{array}{l}\text { Receipt of } \\
\text { chemotherapy } \\
\text { OR }(95 \% \text { CI })\end{array}$ & $\begin{array}{l}\text { Receipt of } \\
\text { radiation } \\
\text { OR }(95 \% \mathrm{CI})\end{array}$ \\
\hline \multicolumn{5}{|l|}{ Race/ethnicity } \\
\hline Non-Hispanic white & 1.0 & 1.0 & 1.0 & 1.0 \\
\hline African American & $1.22(0.59-2.55)$ & $0.93(0.46-1.89)$ & $0.61(0.37-0.95)$ & $0.74(0.42-1.30)$ \\
\hline Hispanic & $1.30(0.62-2.74)$ & $0.91(0.44-1.89)$ & $0.88(0.55-1.39)$ & $0.50(0.27-0.95)$ \\
\hline Age (Yrs) & $0.98(0.95-1.00)$ & $0.96(0.93-0.98)$ & $0.94(0.92-0.96)$ & 0.97 (0.95-0.99) \\
\hline \multicolumn{5}{|l|}{ Stage } \\
\hline Local & 1.0 & 1.0 & 1.0 & 1.0 \\
\hline Regional & $1.0(0.39-2.55)$ & $0.82(0.37-1.82)$ & $2.53(1.01-6.30)$ & $1.35(0.54-3.36)$ \\
\hline Distant & $0.15(0.05-0.42)$ & $0.08(0.03-0.22)$ & $1.74(0.73-4.14)$ & $0.19(0.07-0.49)$ \\
\hline Unstaged & $0.32(0.08-1.32)$ & $0.03(0.01-0.17)$ & $1.20(0.40-3.62)$ & $0.25(0.07-0.88)$ \\
\hline \multicolumn{5}{|c|}{ Charlson comorbidity score } \\
\hline 0 & 1.0 & 1.0 & - & - \\
\hline 1 & $0.62(0.25-1.51)$ & $0.72(0.30-1.71)$ & & \\
\hline $2+$ & $0.26(0.08-0.83)$ & $0.28(0.09-0.84)$ & & \\
\hline \multicolumn{5}{|l|}{ Size of primary tumor } \\
\hline$<3 \mathrm{~cm}$ & 1.0 & 1.0 & 1.0 & 1.0 \\
\hline$>3 \mathrm{~cm}$ & $0.32(0.14-0.74)$ & $0.32(0.14-0.72)$ & $0.81(0.40-1.66)$ & $0.88(0.39-2.01)$ \\
\hline Unknown size & $0.08(0.03-0.23)$ & $0.07(0.02-0.19)$ & $0.75(0.36-1.60)$ & $0.47(0.19-1.16)$ \\
\hline \multicolumn{5}{|l|}{ Insurance status } \\
\hline Insured & 1.0 & 1.0 & 1.0 & 1.0 \\
\hline Uninsured & $0.09(0.01-0.62)$ & $0.07(0.01-0.49)$ & $0.36(0.11-1.21)$ & $1.82(0.56-5.96)$ \\
\hline
\end{tabular}

Note: Comorbidity was significantly associated with the receipt of a recommendation and receipt of cancer directed surgery only.

$\mathrm{OR}$, odds ratio; $\mathrm{CI}$, confidence interval.

\section{Discussion}

Generally only patients with pancreatic cancer with localized disease are considered potentially curable. ${ }^{18}$ Treatment of patients with locally advanced and metastatic disease therefore is generally for palliation. ${ }^{11}$ After adjusting for other clinical and demographic variables African Americans were less often given chemotherapy and Hispanics less often received radiation than non-Hispanic whites. Chemotherapy can relieve symptoms, ${ }^{19}$ improve functional status, ${ }^{6}$ and slightly improves survival among patients with advanced pancreatic cancer ${ }^{20,21}$ compared to the best supportive care or symptom management only. ${ }^{19}$ Chemotherapy, although the most frequently received treatment among patients in this study, was significantly less frequently received by African American patients compared to non-Hispanic white patients. This difference was not explained by differences in clinical or demographic characteristics.

A possible explanation for the racial/ethnic differences in care could be differences in provider referral to a medical oncologist. As Luo et al. ${ }^{22}$ note, medical oncology referral is one of the most important determinants of the receipt of chemotherapy. However, other studies have found a lower receipt of chemotherapy for African Americans compared to non-Hispanic whites although there were no differences in the receipt of a consultation with a medical oncologist. ${ }^{23}$ Another explanation is that African American and Hispanic patients may have been palliated with other treatments. It is unlikely, however, that treatment with radiation was used in lieu of chemotherapy as less than $17 \%$ of African Americans received radiation, which was similar to the rates among Hispanics and non-Hispanic whites. It is also possible but unlikely that pain medication or other supportive care may have been more frequently used by African Americans and Hispanics, however, this could not be directly assessed in this study. Differences in patient refusal of chemotherapy would also not explain differences in the receipt of chemotherapy as the rates of refusal were similar across the race/ethnic groups.

Reasons for the racial/ethnic variation in the receipt of radiation are not clear. Radiation is seldom used as a standalone treatment for pancreatic cancer. Treatment of pancreatic with radiation is usually done in combination with chemotherapy. Therefore, it is not clear whether or not Hispanic patients received less appropriate care because of the lower use of radiation.

We also observed a trend toward the lower receipt of a recommendation for and receipt of cancer-directed surgery and a nonsignificant lower use of chemotherapy among uninsured patients in this study. The use of either chemotherapy or radiation also decreased with age.

Overall, only $14 \%$ of patients received cancer-directed surgery that did not significantly differ by race/ethnicity. This finding is consistent with other reports of the low resectability of pancreatic tumors. ${ }^{24,} 25$

Although a slightly lower proportion of African Americans received cancer-directed surgery, results from the multivariate analyses suggest that differences in size of the primary tumor, stage and insurance status contributed to racial/ethnic differences in the receipt of cancer-directed surgery. In another study Eloubeidi ${ }^{26}$ found that African Americans were more likely to refuse surgery; however, in our study there was little racial/ethnic variation in the proportion of patients that 
refused surgery. Our data show that receipt of cancer-directed surgery also varied significantly by stage, Charlson comorbidity score, size of the tumor, and insurance status.

Racial/ethnic differences in receipt of treatment of other cancer sites have primarily focused on cancer directed surgery and adjuvant therapy with curative intent and thus is sometimes explained by differences in stage at diagnosis. Because of the low number of patients with pancreatic cancer diagnosed with early stage disease or that can be treated surgically, treatment frequently focuses on palliation of symptoms including pain. Approximately $70 \%-80 \%$ of patients with pancreatic cancer have pain at the time of diagnosis which increases to approximately $90 \%$ among patients with advanced pancreatic cancer. ${ }^{27}$ We therefore believe that most of the treatment recorded in this study was for palliation. The low number of patients who received resection and the less frequent use of chemotherapy and radiation among African Americans and Hispanics, respectively, suggest that there may be racial/ethnic disparities in receipt of palliative care for pancreatic cancer. Future research studies are needed that further examine racial/ethnic variation in receipt of palliative care among patients treated for pancreatic cancer.

We also examined disease-specific and overall survival to assess whether racial/ethnic differences in the receipt of chemotherapy and other treatment might be due to earlier mortality among African Americans. Our results showed no significant differences by race/ethnicity with regard to either overall or disease-specific survival which suggests that earlier mortality is unlikely to account for differences noted in the receipt of cancer-directed surgery, chemotherapy or radiation among patients with pancreatic cancer in this study.

\section{Study limitations}

Although we had no information on patient preferences for treatment we did have information regarding treatment refusals. Since this is often a rapidly fatal disease patients may have strong opinions on the type of therapy they would be willing to accept. Because we found little difference between the race/ethnic groups with regard to treatment refusals it is unlikely that this explains much of the treatment differences we observed. We are also unable to determine why patients who had surgery recommended did not have it performed. It is possible that further diagnostic imaging after the initial assessment may have revealed contraindications to surgery, that the patient's condition deteriorated before surgery could be performed, or that other contraindications to surgery were found after the opening incision.

Hispanic ethnicity was assigned to about $1.2 \%$ of all patients with pancreatic cancer because they had Hispanic surnames but a country of origin was not identified. A recent study comparing SEER-assigned ethnicity with self-reported race/ethnicity has estimated SEER sensitivity to be $79 \%$ for Hispanic ethnicity and $90 \%$ for African American and white race. $^{28}$

The small sample sizes should be considered in the interpretation of the findings from the analyses containing health insurance status. Only 23 patients in this study were uninsured. A higher percentage of uninsured patients had contraindications to surgery which partially explains the lower receipt of a recommendation for cancer-directed surgery. Nonetheless, these data suggest that there is a need to take a closer look at the role of the lack of health insurance at the time of diagnosis among cancer patients and the role it plays the prevalence of contraindications to treatment. We were also unable to examine site of care due to insufficient sample size.

\section{Conclusion}

Consistent with the observations of other studies, only approximately $14 \%$ of patients with pancreatic cancer in this study presented with resectable tumors. Differences in the overall pattern of care observed across the racial/ethnic groups were not fully accounted for by differences in clinical characteristics. More research may be needed to fully understand the role that race/ethnicity, age, insurance status, and patient preference play in the receipt of palliative care for pancreatic cancer. Utilization patterns of other palliative measures for pancreatic cancer, such as pain medications, nerve blocks, and other procedures that alleviate the pain, reduce symptoms and discomfort, and their acceptability among diverse patients should also be investigated.

\section{Acknowledgments}

The authors thank the participating SEER registries without whom this research would not have been possible. The authors also thank Dr. Rachel Ballard-Barbash, John Kerner, and Martin L. Brown of the National Cancer Institute for their review of the draft manuscript and Jennifer Stevens of Information Management Services for her assistance with the data analysis. Funding was provided by National Cancer Institute (NCI) Contract Numbers: N01-PC-35133, N01PC-35135, N01-PC-35136, N01-PC-35137, N01-PC-35138, N01-PC-35139, N01-PC-35141, N01-PC-35142, N01-PC-35143, N01-PC-35145; HHS Contract: Numbers: HHSN261200544 002C, HHSN261200544003C, HHSN261200544004C, HHSN 261200544005C; and Interagency agreement Y1-PC-4033.

\section{Author Disclosure Statement}

No competing financial interests exist.

\section{References}

1. American Cancer Society: Cancer Facts \& Figures 2008. Atlanta, GA: American Cancer Society, 2008.

2. Ries LAG, Melbert D, Krapcho M, Stinchcomb DG, Howlader N, Horner MJ, Mariotto A, Miller BA, Feuer EJ, Altekruse SF, Lewis DR, Clegg L, Eisner MP, Reichman M, Edwards BK (eds): SEER Cancer Statistics Review, 19752005. http://seer.cancer.gov/csr/1975_2005/, based on November 2007 SEER data submission, posted to the SEER website, 2008. National Cancer Institute. Bethesda, MD (Last accessed May 28, 2009).

3. Mancuso A, Calabro F, Sternberg CN: Current therapies and advances in the treatment of pancreatic cancer. Crit Rev Oncol Hematol 2006;58:231-241.

4. Erickson RA. Pancreatic Cancer. Updated December 15, 2005. www.emedicine.com/med/topic1712.htm (Last accessed November 13, 2006).

5. Kamar FG, Grossbard ML, Kozuch PS: Metastatic pancreatic cancer: Emerging strategies in chemotherapy and palliative care. Oncologist 2003;8:18-34.

6. Shore S, Raraty MMGT, Ghaneh P, Neoptolemos JP: Review article: Chemotherapy for pancreatic cancer. Ailment Pharmacol Ther 2003;18:1049-1069. 
7. Nakakura EK, Warren RS: Palliative care for patients with advanced pancreatic and biliary cancers. Surg Oncol 2007;16:293-297.

8. Vulfovich M, Roch-Lima C: Novel advances in pancreatic cancer treatment. Expert Rev Anticancer Ther 2008;8:9931002.

9. Bahra M, Jacob D: Surgical palliation of advanced pancreatic cancer. Recent Results Cancer Res 2008;177:111-120.

10. Earle CC, Agboola O, Maroun J, Zuraw L; Gastrointestinal Cancer Disease Site Group: The treatment of locally advanced pancreatic cancer. Practice guideline Report \#2-7. Program in evidenced-based care. www.guideline.gov/ summary/summary.aspx?doc_id $=5585$ (Last accessed February 11,2009 ).

11. National Comprehensive Cancer Network, Inc. Practice Guidelines in Oncology - v.1.2008. Pancreatic Adenocarcinoma. www.nccn.org/professionals/physician_gls/PDF/ pancreatic.pdf (Last accessed February 11, 2009).

12. Smedley BD, Stith AY, Nelson AR (eds): Unequal Treatment: Confronting Racial and Ethnic Disparities in Health Care. Committee on Understanding and Elimination Racial and Ethnic Disparities in Health Care. Health Board on Science Policy. Institute of Medicine. Washington, D.C.: National Academies Press, 2003.

13. Shavers VL, Brown ML: Racial/ethnic disparities in the receipt of cancer treatment. J Natl Cancer Inst 2002;94:334-357.

14. Bach PB, Cramer LD, Warren JL, Begg CB: Racial differences in the treatment of early stage lung cancer. N Engl J Med 341:1198-205.

15. Rabow MW, Dibble SL: Ethnic differences in pain among outpatients with terminal and end-stage chronic illness. Pain Med 2005;6:235-241.

16. Connor SR, Elwert F, Spence, Christakis NA: Racial disparity in hospice use in the United States in 2002. Palliat Med 1008;22:205-213.

17. O'Mara A, Arenella C: Minority representation, prevalence of symptoms and utilization of services in a large metropolitan hospice. J Pain Sympton Manage 2001;290-297.

18. Pierantoni C, Pagliacci A, Scartozzi M, Berardi R, Bianconi M, Cascinu S. Pancreatic cancer: Progress in cancer therapy. Crit Rev Oncol Hematol 2008;67:27-38.

19. Desai SP, Zalupski MM: Pancreatic cancer and survival: The role of chemotherapy. Cancer News. www.cancernews.com/ data/Article/323.asp (Last accessed September 30, 2008).

20. Molinari M, Helton WS, Espat NJ: Palliative strategies for locally advanced unresectable and metastatic pancreatic cancer. Surg Clin North Am 2001;81:651-666.
21. Polati E, Finco G, Gottin L, Bassi C, Pederzoli P, Ischia S: Prospective randomized double-blind trial of neurolytic coeliac plexus block in patients with pancreatic cancer. Br J Surg 1998;85:199-201.

22. Luo R, Giordano SH, Freeman JL, Zhang D, Goodwin JS: Referral to medical oncology: A crucial step in the treatment of older patients with stage III colon cancer. Oncologist 2006;9:1025-1033.

23. Baldwin L, Dobie SA, Billingsley K Cai Y, Wright GE, Dominitz JA, Barlow W, Warren JL, Taplin SH: Explaining black-white differences in receipt of recommended colon cancer treatment. J Natl Cancer Inst 2005;97:1211-1220.

24. National Cancer Institute: Pancreatic Cancer (PDQ): Treatment. Health Professional Version. www.cancer.gov/ cancertopics/pdq/treatment/pancreatic/HealthProfessional (Last accessed November 13, 2006).

25. Cardenes HR, Chiorean EG, DeWitt J, Schmidt M, Loehrer P: Locally advanced pancreatic cancer: current therapeutic approach. Oncologist 2006;11:612-623.

26. Eloubeidi MA, Desmond RA, Wilcox CM, Wilson RJ, Manchikalapati P, Fouad MM, Eltoum I, Vickers SM: Prognostic factors for survival in pancreatic cancer: A population-based study. Am J Surg 2006;192:322-329.

27. Michaels AJ, Draganov PV: Endoscopic ultrasonography guided celiac plexus nerolysis and celiac plexus block in the management of pain due to pancreatic cancer and chronic pancreatitis. World J Gastroenterol 2007;13:3575-3580.

28. Clegg LX, Reichman ME, Hankey BF Miller BA, Lin YD, Johnson NJ, Schwartz SM, Bernstein L, Chen VW, Goodman MT, Gomez SL, Graff JJ, Lynch CF, Lin CC, Edwards BK: Quality of race, Hispanic ethnicity, and immigrant status in population-based cancer registry data: Implications for health disparity studies. Cancer Causes Control 2007;18: 177-187.
Address correspondence to: Vickie L. Shavers, Ph.D. Applied Research Program National Cancer Institute 6130 Executive Boulevard EPN Room 4005 Bethesda, MD 20892

E-mail: shaversv@mail.nih.gov 